\title{
A Quantitative Study of the Coexistence of Peptides in Varicosities Within the Superficial Laminae of the Dorsal Horn of the Rat Spinal Cord
}

\author{
Mary M. Tuchscherer ${ }^{1, a}$ and Virginia S. Seybold ${ }^{1,2}$ \\ 'Department of Cell Biology and Neuroanatomy and ${ }^{2}$ Graduate Program in Neuroscience, University of Minnesota, \\ Minneapolis, MN 55455
}

\begin{abstract}
While several peptides have been shown to coexist in perikarya within dorsal root ganglia of rat, coexistence of peptides has not been confirmed in axons associated with these neurons. In this study, the coexistence of substance P (SP) with somatostatin (SOM), calcitonin gene-related peptide (CGRP), dynorphin A 1-8 (DYN), neurotensin (NT), galanin (GAL), and 5-HT in varicosities was visualized using fluorescence immunohistochemistry. Densities of immunoreactive varicosities within laminae I and II of the dorsal horn of the rat spinal cord were quantified by computer-assisted image analysis. Decreases in densities of immunoreactive varicosities as a result of multiple unilateral dorsal rhizotomies were used to determine proportions of immunoreactive varicosities associated with primary afferent neurons. Three observations were made. (1) Dorsal rhizotomy depleted greater than one-third of the varicosities individually immunoreactive for SP, SOM, GAL, or DYN, confirming the association of these peptides with primary afferent neurons. (2) SP coexisted with CGRP, GAL, and DYN in varicosities within the dorsal horn of normal animals. (3) CGRP., SP+CGRP-, and SP+GAL-immunoreactive varicosities were nearly depleted following dorsal rhizotomy. The depletion of these peptides, particularly in combination, indicates that they may be used as markers for varicosities of some primary afferent neurons within the superficial laminae of the dorsal horn of the rat spinal cord.
\end{abstract}

The majority of information concerning the coexistence of peptides in primary afferent neurons has come from studies of dorsal root and cranial nerve ganglia. Coexistence of 2 substances has been documented in rat perikarya (SP+CGRP: Wicsenfcld-Hallin et al., 1984; Lee et al., 1985a, b; Skofitsch and Jacobowitz, 1985b; SP+CCK-8: Dalsgaard et al., 1982; Tuchscherer and Seybold, 1985), and up to 4 substances have been shown to coexist in the guinea pig (SP+CCK + CGRP + DYN: Gibbins et al., 1987) and cat perikarya (SP+CCK: Gibson et al., 1984a;

\footnotetext{
Received Jan. 19, 1988; revised May 4, 1988; accepted May 20, 1988.

We wish to thank Robert P. Elde for his thoughtful comments regarding the manuscript. We also wish to thank Charles K. Knox and R. Carter Carpenter for their assistance in preparing computer programs for image analysis. This work was supported by NS17702 and Northwestern College of Chiropractic Medicine.

Correspondence should be addressed to Dr. Virginia Seybold, University of Minnesota, Department of Cell Biology and Neuroanatomy, 4-135 Jackson Hall, 321 Church Street S.E., Minneapolis, MN 55455.

${ }^{a}$ Present address: Northwestern College of Chiropractic Medicine, 2501 West 84th Street, Bloomington, MN 55431-1599.

Copyright (C) 1989 Society for Neuroscience $0270-6474 / 89 / 010195-11 \$ 02.00 / 0$
}

SP + CCK + SOM + VIP: Leah et al., 1985). While data concerning patterns of coexistence of peptides are useful in categorizing populations of primary afferent neurons, it is also of interest to determine the significance that corelease of these substances may have for synaptic transmission. Before pursuing physiological studies, it is important to confirm whether combinations of peptides that coexist in neuronal perikarya are also present in varicosities of primary afferent neurons.

One cannot assume that immunoreactivity present within a perikaryon will also be present within axonal varicosities associated with the neuron. An antigenic determinant visualized in a neuronal perikaryon by immunohistochemistry is likely to be contained in a precursor protein. In some neurons, the precursor molecule may be processed during axonal transport to products that no longer contain the recognizable amino acid sequence. For example, somatostatin-like immunoreactivity has been visualized within neurons of the reticular nucleus of the thalamus (Graybiel and Elde, 1983). The majority of the neurons within this nucleus project to the dorsal thalamus. However, somatostatin-immunoreactive varicosities are not found within this region (Graybiel and Elde, 1983).

Conversely, posttranslational processing during axonal transport may create a determinant used in antibody recognition. The density of dynorphin B-immunoreactive varicosities within the cat spinal cord is decreased following dorsal rhizotomy, suggesting a population of primary afferent neurons contains dynorphin (Basbaum et al., 1986). However, dynorphin-immunoreactive perikarya have not been visualized to date in cat dorsal root ganglia (Basbaum et al., 1986; M. G. Garry and V. S. Seybold, unpublished observations). Therefore, it is possible that new patterns of coexistence of peptides may emerge by studying varicosities associated with primary afferent neurons.

In order to determine which peptides may coexist in axonal processes of primary afferent neurons, we studied the coexistence of peptides in varicosities within terminal fields of these neurons in the spinal cord. Visualization of the coexistence of the 2 substances within varicosities was possible by immunonuorescence. The densities of substance P (SP)-, somatostatin (SOM)-, calcitonin gene-related peptide (CGRP)-, galanin (GAL)-, and dynorphin A 1-8 (DYN)-immunoreactive varicosities alone or in combination with SP, were quantified using computer-assisted image analysis. Spinal segment L4 was used in our study. This segment receives input from the sciatic and saphenous nerves whose primary afferent receptive fields are known to be largely somatic (Schmalbruch, 1986).

Within the dorsal horn of segment L4, laminae I and II were 
selected as areas for analysis because the peptides listed above have been localized to predominantly small-diameter perikarya within dorsal root or trigeminal ganglia of the rat (SP: Hökfelt et al., 1975; Tuchscherer and Seybold, 1985; CGRP: Rosenfeld et al., 1983; Gibson et al., 1984a; GAL: Ch'ng et al., 1985; Skofitsch and Jacobowitz, 1985a; DYN 1-8: Botticelli et al., 1981), and small-diameter primary afferent neurons have been shown to terminate within laminae I and II (Kumazawa and Perl, 1976, 1978; Light and Perl, 1979; Sugiura et al., 1986). Decreases in densities of immunoreactive varicosities as a result of miltiple dorsal rhizotomies were used to determine the proportions of varicosities that were associated with primary afferent neurons.

In addition to the 5 peptides outlined above, the densities of neurotensin (NT)- and 5-HT-immunoreactive varicosities were also quantified. Since NT- and 5-HT-immunoreactive varicosities within the dorsal horn of the spinal cord are believed to be entirely from intrinsic (NT: Seybold and Elde, 1982; 5-HT: LaMotte and deLanerolle, 1983) or supraspinal sources (5-HT: Basbaum et al., 1978), their densities were indicators of nonspecific changes due to ischemia or changes of laminae volume as a result of the surgical procedure.

The results of this study indicate that some patterns of peptide coexistence occurring among varicosities within laminae $I$ and II are specific for primary afferent neurons.

\section{Materials and Methods}

Ten adult male (200-300 gm) Sprague-Dawley rats were used in this study. The animals were generally housed in standard wire-mesh cages. Animals that had undergone unilateral dorsal rhizotomy were housed in solid-bottom plastic cages to minimize injury during their recovery. All animals were maintained under $12 \mathrm{hr}$ light/12 hr dark conditions and were allowed access to food ad libitum.

Experimental animals. The animals were divided into 2 groups: a control group $(n=4)$ that received no surgical treatment and an experimental group $(n=6)$. The animals of the experimental group underwent surgery for multiple unilateral dorsal rhizotomies (dorsal roots of spinal levels L1-S1 were transected). The procedure used for the surgical technique has been described in detail elsewhere (Tuchscherer et al., 1987).

On the 10th postoperative day, all 6 animals of the experimental group were vascularly perfused (intraaortically) with Zamboni fixative (Steffanini et al., 1967). The animals of the control group were perfused using the same protocol on the 11 th day. Spinal segment L4 was removed from each animal and was immersed in the same fixative overnight at $4^{\circ} \mathrm{C}$. The tissue was then transferred to a $5 \%$ sucrose solution in $0.1 \mathrm{M}$ phosphate buffer, $\mathrm{pH} 7.2$, at $4^{\circ} \mathrm{C}$ for storage. At the time of microtomy, all 10 L4 segments were embedded in one block. Five micrometer transverse spinal cord sections were cut using a Bright cryostat.

Immunofluorescence microscopy. All tissue sections were stained for simultaneous immunofluorescent localization of 2 substances (Erichsen et al., 1982; Wessendorf and Elde, 1985). Each section was stained for visualization of SP-immunoreactivity (SP-IR) and immunoreactivity of one other substance. The immunohistochemical staining protocol used has been described in detail (Tuchscherer et al., 1987). Table 1 summarizes the antisera used in the study and the working dilutions at which they were used. The mixture of secondary antibodies contained goat anti-rat IgG labeled with fluorescein isothiocyanate (FITC, Dako Chemical, 1/20 dilution) and goat anti-rabbit IgG labeled with lissamine rhodamine sulfanyl chloride (L-RSC, Dako Chemical, 1/10 dilution). The sectioris were viewed and photographed with an Olympus $\mathrm{BH}-2$ RFL fluorescence microscope using epi-illumination. FITC and L-RSC were visualized independently using selective filter combinations as described previously (Tuchscherer et al., 1987).

Characterization of the antisera. Based on our experience, no one model has uniformally provided data on cross-reactivity of antisera that are consistent with the visualization of endogenous antigens immobi- lized within tissue sections. Therefore, we have used 2 approaches, in addition to observations made on tissue sections, to draw conclusions regarding known antigens that our antisera may be visualizing within the material being analyzed. Several of the antisera used in this study have been used by our laboratory for many years, and their characterizations have been previously described (see Table 1). Data in these studies indicated each antiserum was specific for its homologous antigen. Two of the antisera, rabbit anti-CGRP and rabbit anti-galanin, have not been previously characterized by us; thus, data on their cross-reactivities are reported here.

First, absorption controls were performed. When each diluted primary antiserum or antibody was treated for 6-8 hr with the homologous antigen (10 $\mu \mathrm{M}$ in diluted serum), no positive staining was observed in sections of the spinal cord. Next, the model system of Larsson (1981) was used to survey the cross-reactivity of the GAL and CGRP antisera against antigens known to be present in the dorsal horn of the spinal cord. The antigens included: bombesin, CGRP, cholecystokinin-octapeptide, dynorphin A (1-8), leucine-enkephalin, methionine-enkephalin, GAL, neurotensin, oxytocin, 5-HT conjugated to BSA (5-HT-BSA), SOM, substance K, SP, thyrotropin-releasing hormone, vasopressin, and vasoactive intestinal polypeptide. Cross-reactivity to $1 \mathrm{nmol}$ of each heterologous peptide was determined. The primary antisera were used at a concentration of $1 / 1000$, and immunostaining was visualized with the peroxidase antiperoxidase (PAP) approach (Sternberger et al., 1970). Using this model, the GAL antiserum was determined to recognize GAL, alone, while the CGRP antiserum exhibited cross-reactivity to GAL, 5-HT-BSA, SOM, substance K, or SP. The cross-reactivity of the antiserum to 5-HT-BSA is believed to be due to BSA, since the antiserum was generated against a CGRP-BSA conjugate and the antiserum visualized BSA, alone.

As an additional assessment of the cross-reactivity of the CGRP antiserum, heterologous absorption controls were carried out on rat spinal cord and trigeminal ganglia. The CGRP antiserum was used at $1 / 100$, and individual aliquots of this dilution were preincubated with $10 \mu \mathrm{M}$ concentrations of GAL, 5-HT-BSA, SOM, substance K, and SP. Immunostaining was visualized by immunofluorescence. Absorption with $10 \mu \mathrm{M}$ subsiance $\mathrm{K}$, SP, or 5-HT-BSA caused no diminution of the intensity or density of CGRP-immunoreactive varicosities in the superficial laminae of the dorsal horn of the spinal cord or immunoreactive perikarya in the ganglion. Absorption with $10 \mu \mathrm{M}$ SOM caused an apparent decrease in intensity of staining but not density of immunoreactive varicosities.

The ability of the CGRP antiserum to detect peptides known to be in high concentration in selected areas of the brain was also assessed. The CGRP antiserum did not visualize SOM-containing perikarya in the periventricular region of the hypothalamus. These perikarya were intensely labeled with an antibody to SOM after lesion of their axons. In addition, the CGRP antiserum did not visualize SP-containing varicosities in the globus pallidus, where SP immunoreactivity is known to be high.

Based on the total of these observations, we conclude that the data obtained with the CGRP antiserum does not reflect significant crossreactivity for 5-HT, SOM, substance K, or SP in tissue sections. However, we cannot exclude the possibility that some of the varicosities visualized with this antiserum reflect binding of antibodies to GAL.

While the cross-reactivities of the other antisera used in this study have been characterized in earlier reports (see Table 1), limited tests were included for GAL and CGRP, whose discovery has been made only recently. Using the model of Larsson (1981), none of the antisera cross-reacted with $1 \mathrm{nmol}$ CGRP, and the 5-HT antiserum did not detect $1 \mathrm{nmol}$ GAL. However, the SP, SOM, NT, and DYNA (1-8) antisera all detected $1 \mathrm{nmol}$ GAL. The cross-reactivity of the SOM antiserum for GAL was estimated to be between $1-10 \%$. The crossreactivity of the NT antiserum was estimated to be less than $1 \%$. When these antisera were preabsorbed with $10 \mu \mathrm{M}$ GAL, there was no diminution in the density or intensity of SP- or DYN-immunoreactive varicosities in the superficial laminae of the dorsal horn; however, the amount of NT and SOM immunoreactive varicosities was decreased. These observations indicate that data reported for SP- and DYN-immunoreactive varicosities do not reflect significant cross-reactivity with endogenous GAL, but the data for NT- and SOM-immunoreactive varicosities may include detection of some GAL-immunoreactive varicosities. However, experimental results of the present study do not support this (see Discussion).

Tests have been performed on the secondary antisera to establish 
Table 1. Specifications of antisera used

\begin{tabular}{llll} 
Antiserum & Source & Dilution & Reference \\
\hline Rat anti-SP NCL/34HL & Sera Labs & $1: 200$ & Cuello et al., 1979 \\
Rabbit anti-SOM R176-D & R. Elde & $1: 100$ & Sasck ct al., 1984 \\
Rabbit anti-CGRP RPN.1842 Lot 3 & Amersham & $1: 100$ & This study ${ }^{a}$ \\
Rabbit anti-NT Lot 8351022 & Immunonuclear Corp & $1: 100$ & Seybold and Elde, 1982 \\
Rabbit anti-DYN R2-3 & E. Weber & $1: 330$ & Sasek et al., 1984 \\
Rabbit anti-5-HT R196D & R. Elde & $1: 100$ & Maley and Elde, 1982 $_{\text {Rabbit anti-GAL RAS 7153N }}$ \\
\hline
\end{tabular}

${ }^{a}$ See Materials and Methods.

their immunological specificity and have been described previously (Tuchscherer et al., 1987). No cross-reactivity was observed.

Quantification methods. Six tissue sections from each animal were analyzed for immunoreactivity using one section for each of the mixtures of antisera. The tissue sections were chosen at random from a variety of distances through the segment. In preliminary tests of the data, no difference in density of SP-IR varicosities in normal animals was measured among the sections selected for quantification. Therefore, differences in densities of immunoreactive varicosities are not likely to reflect a sampling bias. In each tissuc scction, the region of the superficial laminae at the point deep to the dorsal root entry zone was selected for analysis. As some of the immunoreactivity exhibited medial to lateral differences in distribution, the dorsal root entry zone served as a landmark in all sections. One side of each section from control animals was analyzed. However, in sections from experimental animals, the sides contralateral and ipsilateral to the lesion were analyzed. The working magnification used throughout the study was $250 \times$ actual size. Significant differences in the number of varicosities quantified between control and experimental groups were determined using Student's $t$ test.

Two areas of termination of primary afferent neurons in the dorsal horn of rat spinal segment L4 were studied: (1) laminae I and II-outer (LI/IIo) and (2) lamina II-inner (LIIi). These areas within the field of observation were identified by producing a dark-field image of each tissue section. The arca of least density from the dorsolateral fasciculus (of Lissauer) to the laminae II/III border was then divided such that the dorsal half of the area was operationally defined as LI/IIo, and the ventral half as LIIi. These delineations approximate measurements based on ultrastructural analyses of laminae I and II in the rat (Ribeiro-daSilva and Coimbra, 1982; Ribeiro-da-Silva et al., 1986). Images of immunoreactive varicosities were stored without moving the stage after the dark-field image was obtained.

The procedure used for acquiring irrages was modified from the procedure described previously (Tuchscherer et al., 1987). Briefly, 6 images of each tissue section were created using an International Imaging Systems model 75 image processor, which runs 575 software on a MASSCOMP 535 minicomputer. Images of FITC-labeled immunoreactive varicosities and $\mathrm{L}-\mathrm{RSC}$-labeled immunoreactive varicosities were created individually for LI/IIo and LIII. The FITC-labeled varicosities were assigned the color green, and the L-RSC-labeled varicosities, red. Next, the green and red images for each area were superimposed. Varicosities that contained both the FITC-label and the L-RSC label appeared yellow. Finally, the numbers of green, red, and yellow varicosities within the 2 regions were quantified.

In contrast to the earlier study, which derived the density of immunoreactive varicosities from the total image area of varicosities, a custom computer program was used to quantify images of individual varicosities. The program allowed us to define the minimum image area to count as a varicosity. The average minimum size for all immunoreactive varicosities was empirically determined to be 10 pixels.

In addition to controls which estimated the degree of spurious overlap of immunoreactive varicosities described previously (Tuchscherer et al., 1987), scveral additional controls were developed for this study. Daily changes in microscope lamp alignment or output were monitored using fluorescent microspheres. Before each image-collection session, microspheres $(0.5 \mu \mathrm{m}$ diameter, approximating the size of small peptidergic varicosities; Seybold and Maley, 1984) that had been labeled with the secondary antibodies were viewed with the fluorescence microscope. Images of the fluorescence of the microspheres were produced in the same manner as the fluorescence within the tissue sections. The intensity of the fluorescence of the microspheres as recorded by the digitizing camera was measured. Any alterations in intensity from the previous session were interpreted as differences in illumination, and the lamp was realigned or changed. The silicone-intensified target video camera (DAGE-MTI model 66) used in this study was equipped with controls that allowed changes in gain and amount of contrast in the image delivered to the computer monitor. Preliminary studies were done to identify the optimum settings for the gain and contrast parameters on tissue sections stained with various antisera. After adjustments in microscope illumination of the specimens, these parameters remained constant throughout the study. These control steps decreased the likelihood that changes in densities of immunoreactive varicosities quantified on tissue sections were due to alterations in detection of varicosities by the camera.

To monitor nonspecific differences between tissue sections from different animals, the intensity of the background and the intensity of individual varicosities were measured on each image. The ranges for background staining and the ranges for the least intense to most intense varicosities were not significantly different between sections from control and experimental animals as determined by Student's $t$ test. Finally, a restraint was added in order to eliminate experimenter bias in detection of varicosities. One of the interactive steps in the quantification process required the investigator to assign a minimum intensity level to detect varicosities. Values used in the detection step remained constant throughout the study.

Due to changes in volume caused by dorsal rhizotomy, a correction factor was applied to density data from experimental animals. This factor was derived from measurements of the depth of laminae I and II in each tissue section. The mean depth of laminae I and II in experimental animals was found to be $72 \%$ of the mean depth of laminae I and II in control animals. Therefore, in order to normalize the density determinations, each datum collected from sections of experimental animals was multiplied by 0.72 .

\section{Results}

Densities of varicosities immunoreactive for each substance

A summary of the densities of total peptide- and 5-IIT-immunoreactive (5-HT-IR) varicosities within the superficial laminae of the dorsal horn of control animals and those that had undergone unilateral dorsal rhizotomy (hereafter referred to as experimental animals) is shown in Figure 1. The results demonstrate that in control animals, CGRP-immunoreactive (CGRPIR) varicosities occurred in the highest density within both areas analyzed (LI/IIo and LIIi) compared with the other substances studied. The data also indicate that varicosities immunoreactive for all of the peptides studied and 5-HT occurred at a greater or equal density in LI/IIo compared with LIIi, except NT-immunoreactive (NT-IR) varicosities.

Comparing varicosity densities in control animals (Fig. 1A) with values ipsilateral to dorsal rhizotomies in experimental animals, only the density of NT-IR varicosities was unchanged. Significant reductions in the densities of immunoreactive varicositics occurred for all of the other peptides and 5-HT. The depletion of CGRP-IR varicosities (Fig. 2) was almost complete 


\section{A. Control Animals}

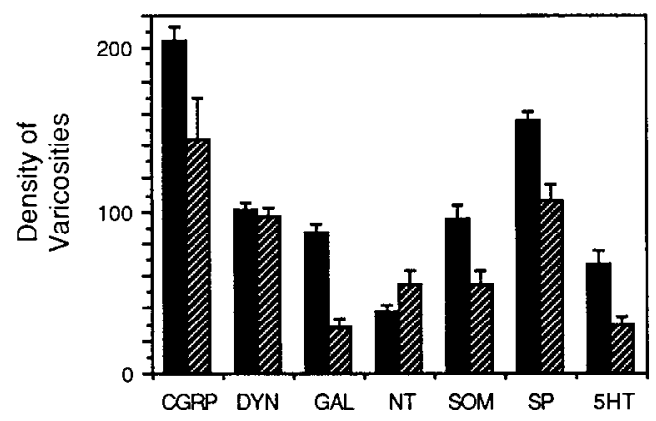

\section{B. Dorsal Rhizotomy Affected Animals}
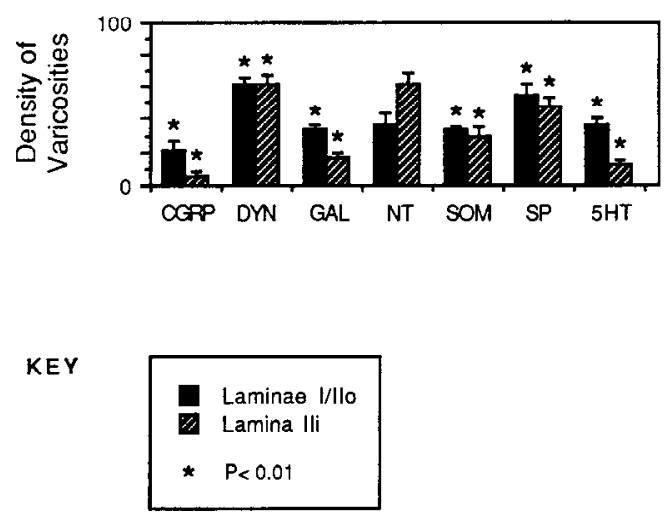

Figure 1. Histograms of densities of total immunoreactive varicosities within laminae $\mathrm{I}$ and $\mathrm{II}_{\text {outer }}\left(\mathrm{LI} / \mathrm{II}\right.$ ) and lamina $\mathrm{II}_{\text {inner }}$ (LIIi) of the dorsal horn of the spinal cord of the rat. The asterisks indicate reduction in density of a population of varicosities immunoreactive for one peptide that is significantly different from the value of the control group at $p<$ 0.01 (Student's $t$ test). Values represent densities of immunoreactive varicosities $/ 6600 \mu \mathrm{m}^{2}$

from both LI/IIo and LIIi. The density of SP-IR varicosities was decreased by approximately $70 \%$ in experimental animals, while the reductions for SOM (see Fig. 3) and GAL (see Fig. 7, $A, C)$ were about $60 \%$. Reductions in density of approximately 50 and $40 \%$ for 5 -HT-IR and DYN-IR varicosities, respectively, were observed in experimental animals. For all substances, values for the side contralateral to the dorsal rhizotomies in experimental animals (data not shown) were not different from the values shown in Figure $1 \mathrm{~A}$.

\section{Coexistence in control animals}

Figure 4 summarizes the densities of varicosities exhibiting coexistence of peptide and 5-HT-immunoreactivities with SP-IR in control animals. With the possible exception of CGRP-IR varicosities, these values reflect varicosities that may arise from brain stem, spinal, and primary afferent sources. SP-IR did not coexist in varicosities containing 5-HT-IR (see Fig. 5), SOMIR, or NT-IR within the areas analyzed. SP-IR coexisted with immunoreactivity for CGRP, GAL (see Fig. 7, $A, B$ ) or DYN (see Fig. 6) within varicosities.

The proportion of total peptide-immunoreactive varicosities containing SP-IR will be compared first. Approximately onehalf of the density of total CGRP-IR varicosities in LI/IIo contained SP-IR, while only one-third of the density of total CGRPIR varicosities in LIIi contained SP-IR. In both LI/IIo and LIIi,
$45 \%$ of the density of total DYN-IR varicosities contained SPIR. Forty percent of the density of the total varicosities immunoreactive for GAL in LI/IIo were immunoreactive for SP, and $34 \%$ of the density of total GAL-IR varicosities in LIIi contained SP-IR.

The proportion of the total SP-IR varicosities containing other peptide immunoreactivities can also be described. In LI/IIo, $50 \%$ of the density of total SP-IR varicosities were immunoreactive for CGRP, while only $25 \%$ of the density of the total SP-IR varicosities contained GAL-IR and $20 \%$ contained DYNIR. In LIIi, one-third of the density of total SP-IR varicosities contained CGRP-IR or DYN-IR, while only one-fifth of the density of total SP-IR varicosities contained GAL-IR.

\section{Cocxistence in varicosities of primary afferent neuron origin}

Figure 8 summarizes the calculated densities of coexistence of peptide- and 5-HT-immunoreactivities with SP-IR in varicosities of primary afferent origin. The results were derived from tissue sections of experimental animals by subtracting data collected from the side ipsilateral to the lesion from data collected from the contralateral side. SP-IR did not coexist with 5-HTIR, SOM-IR, or DYN-IR in varicosities of primary afferent origin. Comparison of Figures 4 and 8 shows that all varicosities that cocontained SP-IR and CGRP-IR or GAL-IR were of primary afferent origin. Approximately $76 \%$ of the density of SPIR varicosities of primary afferent origin contained CGRP-IR in LI/IIo. One-third of the density of SP-IR varicosities of primary afferent origin contained GAL-IR in LI/IIo. Approximately $50 \%$ of the densities of GAL-IR or CGRP-IR varicosities of primary afferent origin contained SP-IR in LI/IIo.

\section{Discussion}

This study employed computer-assisted image processing to quantify densities of CGRP-, DYN-, GAL-, NT-, SOM-, SP-, and 5-HT-IR varicosities in 2 distinct regions of the dorsal horn of the spinal cord in normal animals and animals that had undergone unilateral dorsal rhizotomy. The results of this study corroborate and extend the findings of other laboratories using immunohistochemical methods to compare relative densities of peptide immunoreactive varicositics in the dorsal horn of the spinal cord.

\section{Antiserum cross-reactivity}

In light of the data acquired with the antisera on tissue sections in the present study, it is possible to make additional comments concerning the cross-reactivity of antisera with endogenous antigens. It is not likely that the SOM or NT antisera detected GAL within our material since no coexistence of these substances with SP was detected, yet measurable densities of GAL + SP-IR varicosities were detected. It is also unlikely that the DYN antiserum detected GAL in our material since a population of DYN+SP-IR varicosities was not associated with primary afferent neurons. While our quantitative data on immunoreactive varicosities cannot exclude a cross-reactivity of CGRP with endogenous GAL, we do feel the data indicate that the DYN, SP, SOM, 5-HT, and NT antisera do not exhibit cross-reactivity with endogenous forms of the antigens against which the antisera were tested.

\section{Density of immunoreactive varicosities in normal animals}

In studies where densities for similar peptides were compared (Seybold and Elde, 1980; Gibson et al., 1981; Hunt et al., 1981), 

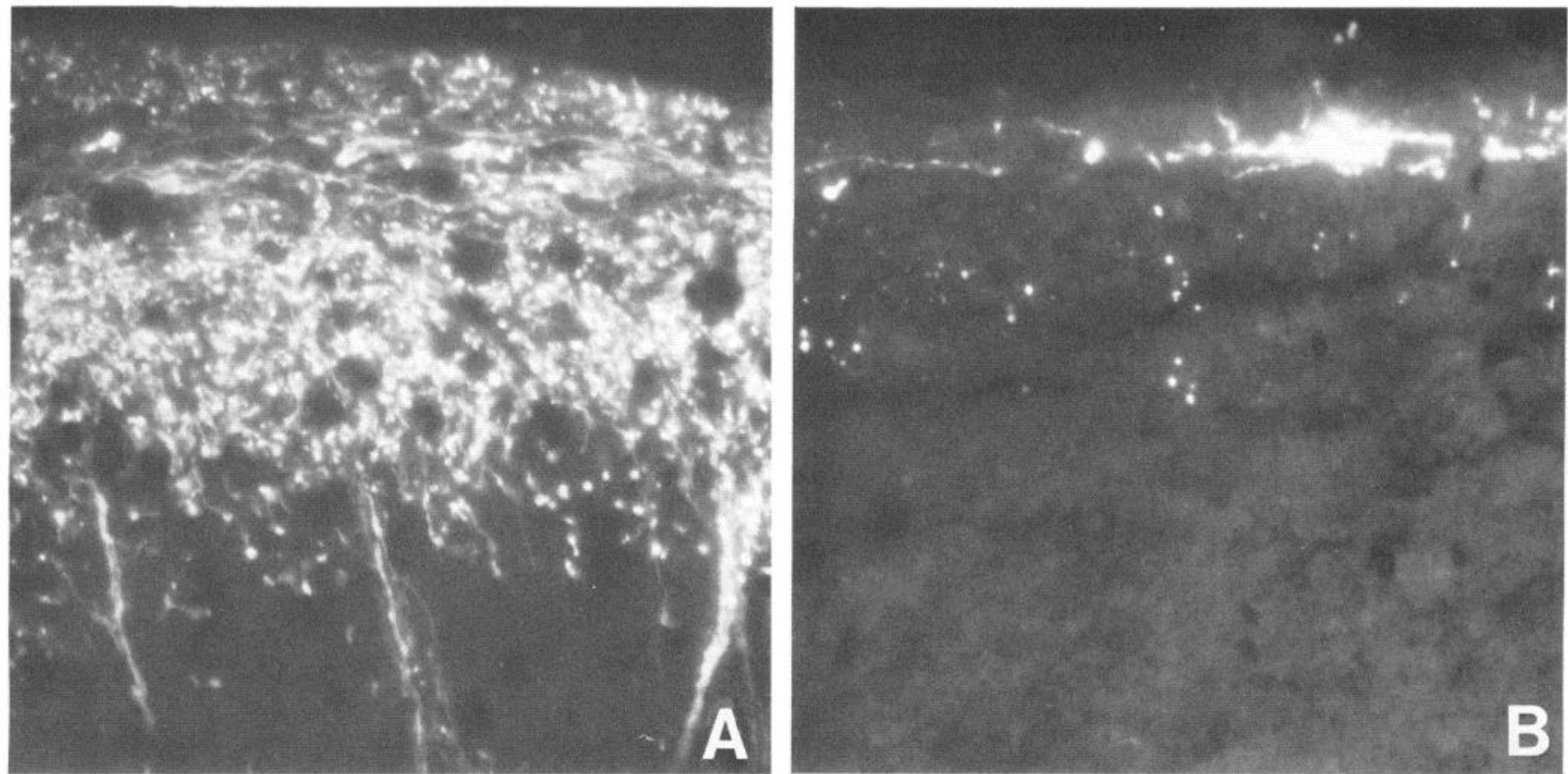

Figure 2. Photomicrographs illustrating the effect of dorsal rhizotomy on the density of CGRP-IR varicosities in the superficial laminae of the dorsal horn. $A$, Control animal; $B$, experimental animal. Magnification, $\times 1130$. Note that deafferentation results in almost complete reduction of CGRP-IR elements from the superficial laminae of the dorsal horn of the spinal cord.

our results are in agreement with descriptions in which the density of SP-IR varicosities is high within both LI/IIo and LIIi, and the density of SOM-IR varicosities is considerably less than that of SP-IR. Our results also agree with descriptions in which the density of SOM-IR varicosities is greater than that of NTIR varicosities in LI/IIo (Seybold and Elde, 1980). Our results also showed that of the peptides studied, only NT-IR varicosities existed at a higher density in LIIi than in LI/IIo. This finding is in agreement with previous reports (Hunt et al., 1981; Seybold and Elde, 1982) in which the superficial laminae of the dorsal horn were also studied separately.

Our study included quantification of densities of CGRP and GAL immunoreactivities. As these peptides have only recently been discovered (Rosenfeld et al., 1983; Tatemoto et al., 1983),
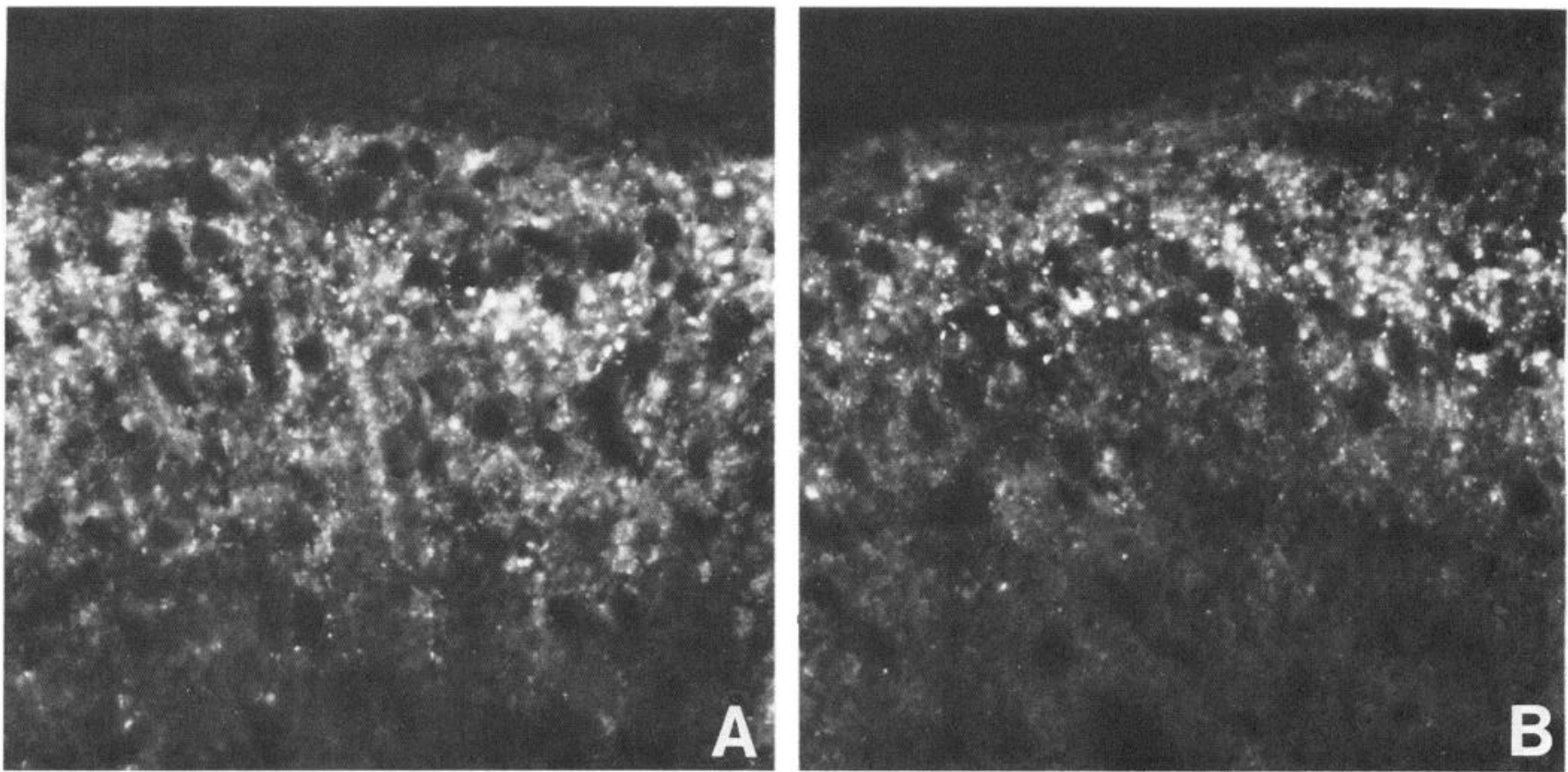

Figure 3. Photomicrographs illustrating the effect of dorsal rhizotomy on the density of SOM-IR varicosities in the superficial laminae of the dorsal horn. $A$, Control animal; $B$, experimental animal. Magnification, $\times 1130$. Note that deafferentation results in a partial reduction of SOM-IR elements in the dorsal horn of the spinal cord. 
Figure 4. Histogram illustrating densities of varicosities immunoreactive for substances alone and densities of varicosities in which substances coexist with SP-IR in the superficial laminae of the dorsal horn. Bars to the left of the zero point reflect densities of varicosities containing one substance alone. Bars to the right of the zero are stacked. In cases where coexistence was observed, those values occur immediately to the right of the zero. Values represent densities of immunoreactive varicosities $/ 6600 \mu \mathrm{m}^{2}$. See key and text for further details.
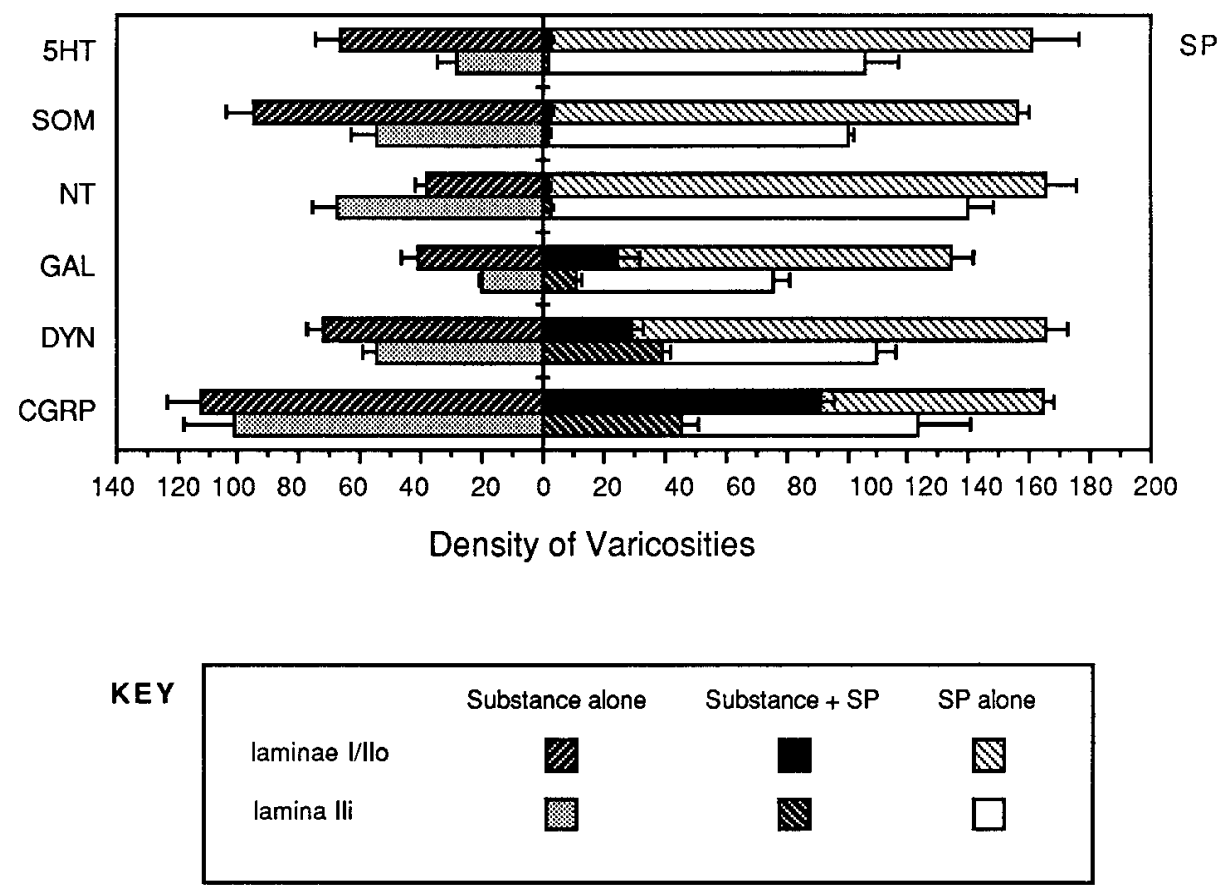

their relative densities have not been directly compared with densities of other substances in the dorsal horn of the spinal cord to date. Our results demonstrated that the density of CGRPIR varicosities was greater than the density of any of the other substances we analyzed for both LI/IIo and LIIi.

\section{Density of immunoreactive varicosities in experimental animals}

Previous studies have reported reductions in the relative densities of many peptide-immunoreactive varicosities in the dorsal horn of the spinal cord as a result of dorsal rhizotomy (for review, see Salt and Hill, 1983; SP: Barber et al., 1979; Jessell et al., 1979; Seybold and Elde, 1980; SOM: Seybold and Elde, 1980; Stine et al., 1982; Schroder, 1984; CGRP: Gibson et al., $1984 a, b)$. Our results corroborate these findings and add new information concerning changes in the relative densities of varicosities immunoreactive for several other peptides. Our results established that the densities of GCRP-, DYN-, GAL-, SOM-, SP-, and 5-HT-IR varicosities were significantly reduced ipsilateral to the lesion in animals that underwent unilateral dorsal rhizotomy. These data are consistent with observations of most of the substances within dorsal root ganglia (SP: Hökfelt et al., 1975; SOM: Hökfelt et al., 1976; CGRP: Rosenfeld et al., 1983; GAL: Skofitsch and Jacobowitz, 1985a; DYN: Sweetnam et al., 1982). However, we cannot conclude that the magnitude of the decrease in each instance is due solely to substances contained in primary afferent axons. The possibility exists that a portion of the decrease reflects a change secondary to the loss of primary afferent neuronal transmission in the spinal cord. In addition, our observation that significant densities of SP- and SOM-IR varicosities remained in LI/IIo and LIII ipsilateral to the lesion in experimental animals complements studies showing intraspinal and/or bulbospinal elements immunoreactive for SP (Bowker et al., 1981; Gibson et al., 1981; Hunt et al., 1981; Johansson et al., 1981) and SOM (Dalsgaard et al., 1981; Schroder, 1984).
Some contradiction exists in the literature regarding the alteration of DYN-IR in the dorsal horn of the spinal cord following dorsal rhizotomy. Although DYN-IR has been localized in dorsal root ganglia of the rat (Botticelli et al., 1981) and mouse (Sweetnam et al., 1982), Botticelli and coworkers (1981) found that dorsal rhizotomy did not alter spinal levels of DYN-IR when measured by radioimmunoassay. Our results, however, showed that the density of DYN-IR varicosities was significantly reduced in both LI/IIo and LIIi in experimental animals compared with levels in normal animals. Differences in experimental approach may account for these divergent results. Immunohistochemical techniques may provide greater sensitivity and resolution for detecting changes in the distribution of immunoreactivity among discrete regions. Our observations regarding DYNA (1-8) parallel those of Basbaum and coworkers (1986). These investigators reported significant reductions in DYNB immunoreactivity from the dorsal horn of the sacral spinal cord of the cat following dorsal rhizotomy as detected by immunohistochemical techniques.

Our results also showed that the density of GAL-IR varicositics was significantly reduced ipsilatcral to the lcsion in both LI/IIo and LIIi and that the decrease in density of GAL-IR varicosities was greater in LI/IIo than in LIIi. These results extend the findings of an earlier report demonstrating that GALIR in the dorsal horn of the spinal cord was reduced following neonatal application of capsaicin (Ch'ng et al., 1985).

An unexpected result of dorsal rhizotomy was a decrease in the density of 5-HT-IR varicosities from the superficial laminae of the dorsal horn. We interpret this as a change secondary to deafferentation. Although there is one report of 5-HT immunoreactivity in primary afferent neurons (Kai-Kai and Keen, 1985), the validity of the data may be questioned since 5-hydroxytryptophan treatment was used to enhance 5-HT immunoreactivity. This substance may be nonspecifically taken up and decarboxylated by a catecholamine neuron. Thus, this approach may have labeled catecholamine-positive neurons, 

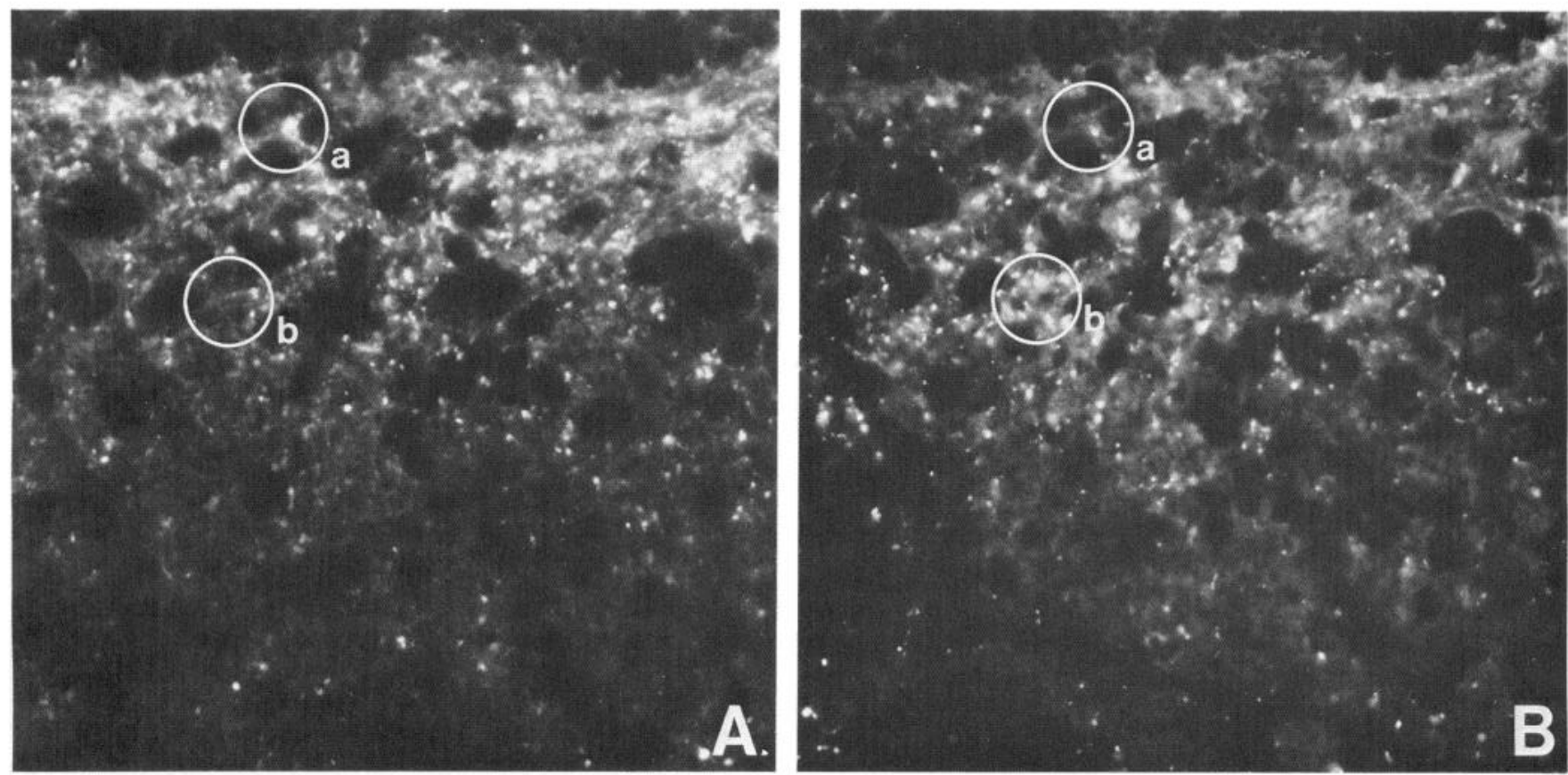

Figure 5. Photomicrographs illustrating that SP-IR and 5-HT-IR do not coexist in the superficial laminae of the dorsal horn. $A$, SP-IR; $B$, 5-HTIR. Circles labeled $a$ in both hotomicrographs indicate one field in which SP-IR varicosities do not contain 5-HT-IR. Circles labeled $b$ in both photomicrographs indicate one field in which 5-HT-IR varicosities do not contain SP-IR. Magnification, $\times 1130$.

which have been shown to exist in sensory ganglia on the basis of tyrosine hydroxylase immunoreactivity (Price and Mudge, 1983). Other reports have established that 5-HT-IR elements in the dorsal horn of the spinal cord arise primarily from bulbospinal pathways (Basbaum et al., 1978; Basbaum and Fields, 1979; Bowker et al., 1981) or from projections of intraspinal neurons that exist ventral to the central canal (LaMotte and deLanerolle, 1983). Our data are consistent with a recent report that SP does not coexist with 5 -HT in varicosities within the superficial laminae of the dorsal horn (Wessendorf and Elde, 1987). It has been suggested that some 5-HT terminals modify primary afferent processing (see LaMotte, 1986, for review).
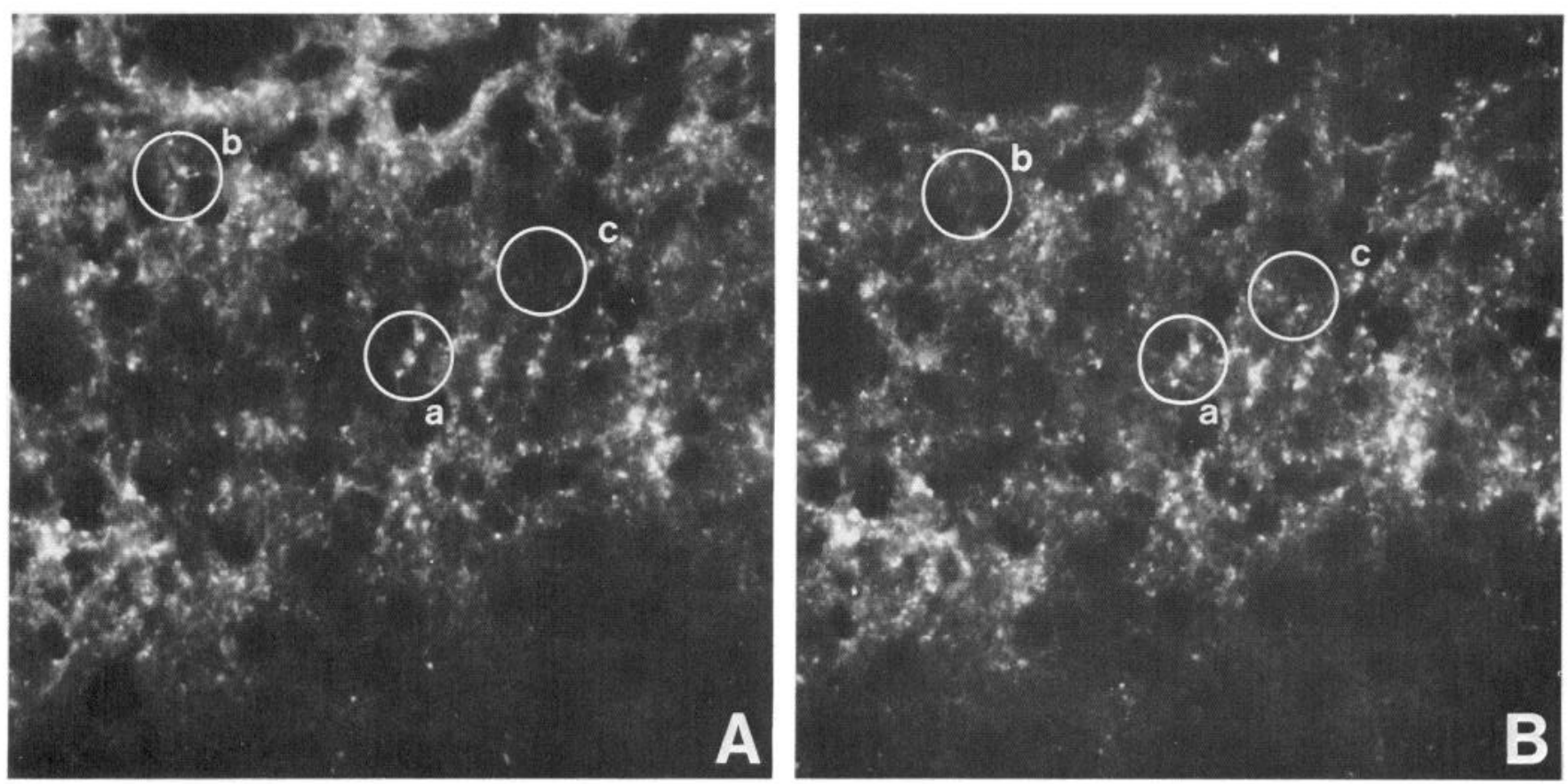

Figure 6. Photomicrographs illustrating that SP-IR and DYN-IR coexist in some varicosities within the superficial laminae of the dorsal horn. $A$, SP-IR; $B$, DYN-IR. Circles labeled $a$ in both photomicrographs indicate one field in which SP-IR and DYN-IR coexist within varicosities. Circles labeled $b$ indicate one field in which several SP-IR varicosities do not contain DYN-IR. Circles labeled $c$ indicate one field in which several DYN-IR varicosities do not contain SP-IR. Magnification, $\times 1130$. 

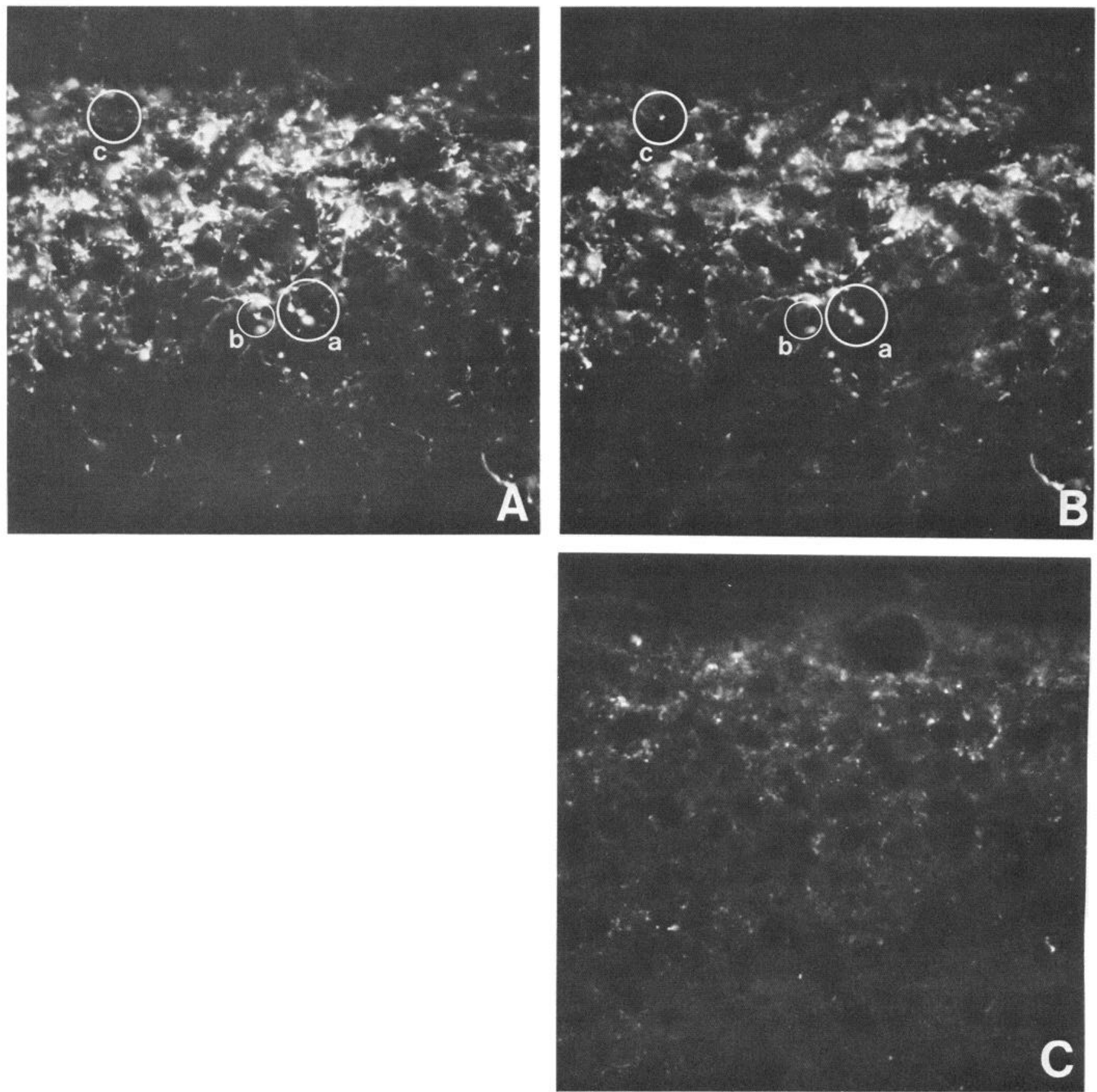

Figure 7. Photomicrographs illustrating coexistence of SP-IR and GAL-IR in some varicosities $(A$ and $B)$ and the effect of dorsal rhizotomy on the density of GAL-IR ( $B$ and $C$ ) within the superficial laminae of the dorsal horn. $A$, SP-IR of a control animal; $B$, GAL-IR within the same section as $A ; C$, GAL-IR of an experimental animal. Circles labeled $a$ indicate one field in which varicosities exhibit immunoreactivity for both $\mathrm{SP}$ and GAL. Circles labeled $b$ indicate one field in which some varicosities are immunoreactive for SP but not GAL. Circles labeled $c$ indicate one field in which some varicosities are immunoreactive for GAL but not for SP. In $C$, note that deafferentation results in a partial reduction in GAL-IR elements in the dorsal horn of the spinal cord. Magnification, $\times 1130$.

Therefore, it is possible that loss of primary afferent neuron input causes a reduction in expression of 5-HT-IR within elements that contact primary afferent terminals.

Coexistence of peptides in varicosities within laminae I and II in normal and experimental animals

Our results confirm studies showing that SP-IR coexists with CGRP-IR in primary afferent neuron perikarya [Wiesenfeld-
Hallin et al., 1984 (guinea pig); Gibson et al., 1984a (man); Lee et al., 1985a, b (rat)] and in peripheral processes of sensory neurons of guinea pigs (Gibbins et al., 1987). However, our report represents the first evidence of varicosities that contain both SP and CGRP (SP+CGRP), immunoreactivity in the superficial laminae of the dorsal horn of the rat. Furthermore, we have shown that the total density of SP+CGRP varicosities in LI/IIo and LIIi of the dorsal horn of the spinal cord arose from 

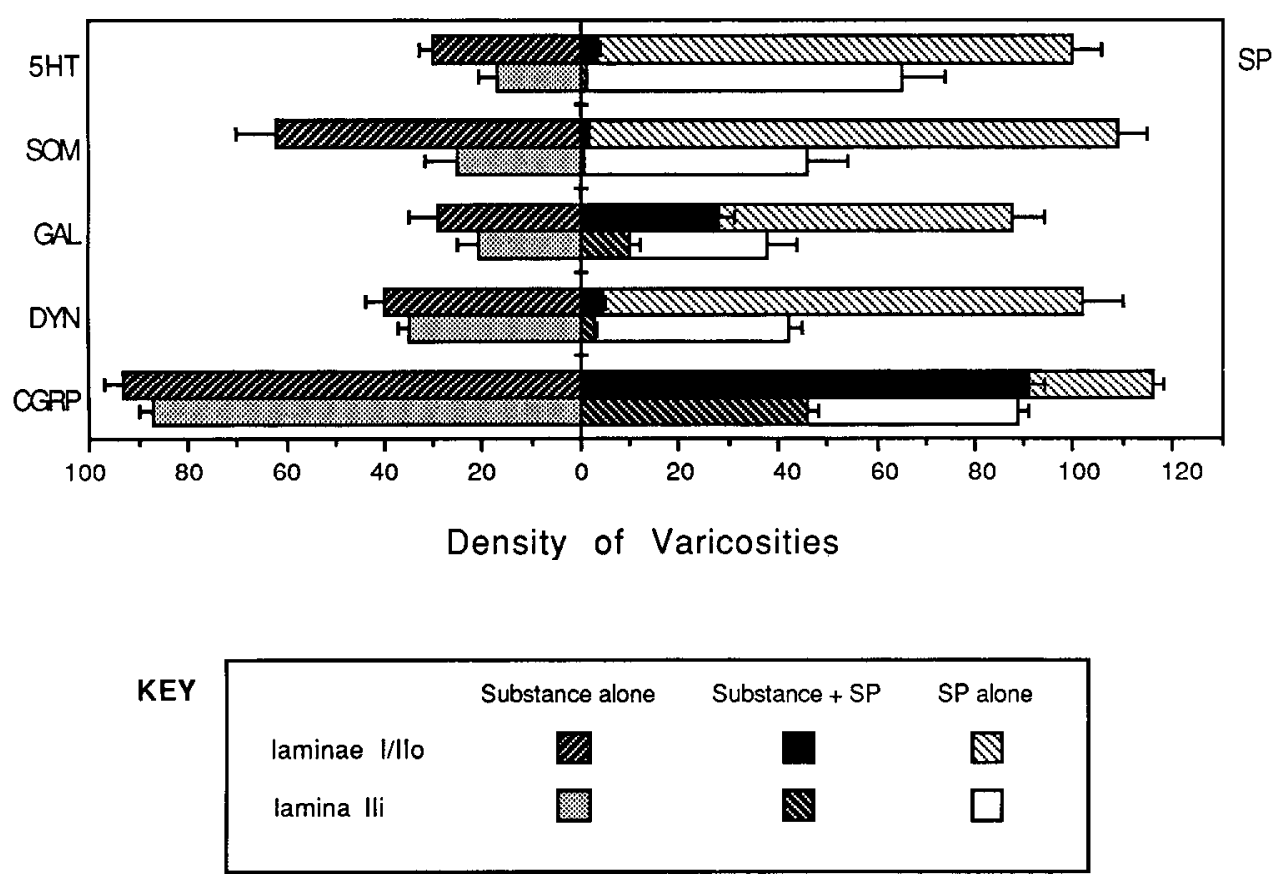

Figure 8. Histogram illustrating coexistence of peptides and 5-HT with substance $\mathbf{P}$ in primary afferent varicosities within the superficial laminae of the dorsal horn of the spinal cord. Bars to the left of the zero point reflect densities of varicosities containing one substance alone. Bars to the right of the zero are stacked. In cases where coexistence was observed, those values occur immediately to the right of the zero. Values represent densities of immunoreactive varicosities/6600 $\mu \mathrm{m}^{2}$. See key and text for further information. primary afferent neurons as dorsal rhizotomy induced complete reduction of these varicosities from the areas studied.

Although studies carried out in cat have demonstrated the coexistence of SOM and SP immunoreactivity in primary afferent perikarya (Leah et al., 1985), our studies determined that SP and SOM immunoreactivity do not coexist in varicosities of the dorsal horn of the spinal cord of rat. This was observed in both control and experimental animals, and confirms earlier studies in the rat (Hökfelt et al., 1976; Tuchscherer and Seybold, 1985), which demonstrated separate populations of perikarya immunoreactive for SP and SOM within dorsal root ganglia.

The present study demonstrated 2 previously unreported instances of coexistence of peptide immunoreactivities. First, we have shown that SP and GAL (SP+GAL) immunoreactivities coexisted in varicosities within LI/IIo and LIIi of the dorsal horn of the spinal cord. Further, as was the case for SP+CGRP varicosities, the population of $S P+G A L$ varicosities was found to be almost entirely of primary afferent origin. The SP+GAL population of primary afferent varicosities was considerably smaller than the SP+CGRP population of primary afferent varicosities. Second, we have shown that SP and DYN (SP+DYN) immunoreactivities also coexisted in varicosities of LI/IIo and LII of the dorsal horn of the spinal cord. In this case, however, dorsal rhizotomy had no effect on the density of SP + DYN varicosities in either area studied. Although a portion of the total density of DYN-IR varicosities was reduced by dorsal rhizotomy - and, therefore, some DYN-IR varicosities are likely to be of primary afferent origin - the population of SP $+\mathrm{DYN}$ varicosities more likely arises from either descending or intraspinal systems of input. The sources of the SP+DYN elements have not been addressed in the present study, though previous studies have shown that DYN-IR perikarya (Miller and Seybold, 1987) and SP-IR perikarya (Hökfelt et al., 1975) are present within the superficial laminae of the dorsal horn of the rat.

\section{Primary afferent neuron markers}

Recently, several laboratories have begun to approach the complexity of the primary afferent system from an "organizational" point of view by suggesting that the variety of peptides localized in small-diameter perikarya may serve as markers for specific populations of functionally described primary afferent neurons. Vasoactive intestinal polypeptide and DYN, for example, have been localized preferentially to levels of the spinal cord that receive visceral afferents (Basbaum and Glazer, 1983; Honda et al., 1983; Gibson et al., 1984b; Kuo et al., 1985). It has been suggested that these peptides may be markers for primary afferent neurons associated with viscera. Similarly, individual patterns of coexistence of peptides in primary afferent perikarya and peripheral processes of these neurons have been observed within specific peripheral targets (Gibbins et al., 1987). In this study, we have presented data suggesting that patterns of peptide immunoreactivity observed within the spinal cord may also serve as markers of primary afferent neuron processes. We have shown that CGRP alone, SP+CGRP, and SP+GAL varicosities are almost entirely of primary afferent origin. Therefore, these substances in combination may be used as markers of primary afferent neurons in morphological studies that address circuitry in the superficial laminae of the dorsal horn of the spinal cord.

\section{Conclusions}

In summary, the major conclusions to be drawn from this work are the following: (1) Significant proportions of the densities of SP, SOM, GAL, CGRP, and DYN varicosities in I I/IIo and LIIi of the dorsal horn of the rat spinal cord are derived from primary afferent neuron sources; (2) SP+CGRP, SP+GAL, and $\mathrm{SP}+\mathrm{DYN}$ coexist in varicosities within the spinal cord; and (3) densities of CGRP, SP+CGRP, and SP+GAL varicosities in LI/IIo and LII are derived almost entirely from primary afferent neuron sources, and may be considered markers of primary afferent axons in the areas outlined.

\section{References}

Barber, R. P., J. E. Vaughn, J. R. Slemmon, P. M. Salvaterra, E. Roberts, and S. E. Leeman (1979) The origin, distribution, and synaptic relationships of substance $P$ axons in the rat spinal cord. J. Comp. Neurol. 184: 331-352. 
Basbaum, A. I., and H. L. Fields (1979) The origin of descending pathways in the dorsolateral funiculus of the spinal cord of the cat and rat: Further studies on the anatomy of pain modulation. J. Comp. Neurol. 187: 513-532.

Basbaum, A. I., and E. Glazer (1983) Immunoreactive vasoactive intestinal polypeptide is concentrated in the sacral spinal cord: A possible marker for pelvic visceral afferent fibers. Somatosensory Res. 1: 69-82.

Basbaum, A. I., C. H. Clanton, and H. L. Fields (1978) Three bulbospinal pathways from the rostral medulla of the cat: An autoradiographic study of pain modulating systems. J. Comp. Neurol. 178: 209-224.

Basbaum, A. I., L. Cruz, and E. Weber (1986) Immunoreactive dynorphin B in sacral primary afferent fibers of the cat. J. Neurosci. 6: 127-133.

Botticelli, L. J., B. M. Cox, and A. Goldstein (1981) Immunoreactive dynorphin in mammalian spinal cord and dorsal root ganglia. Proc. Natl. Acad. Sci. USA 78: 7783-7786.

Bowker, R. M., H. W. M. Steinbusch, and J. D. Coulter (1981) Serotonin and peptidergic projections to the spinal cord demonstrated by a combined retrograde HRP histochemical staining method. Brain Res. 211: 412-417.

Ch'ng, J. L. C., N. D. Christofides, P. Anand, S. J. Gibson, Y. S. Allen, H. C. Su, K. Tatemoto, J. F. B. Morrison, J. M. Polak, and S. R. Bloom (1985) Distribution of galanin immunoreactivity in the central nervous system and the responses of galanin-containing ncuronal pathways to injury. Neuroscience $16: 343-354$.

Cuello, A. C., G. Galfrè, and C. Milstein (1979) Detection of substance $P$ in the central nervous system by a monoclonal antibody. Proc. Natl. Acad. Sci. USA 7: 3532-3536.

Dalsgaard, C.-J., T. Hökfelt, O. Johansson, and R. Elde (1981) Somatostatin immunoreactive cell bodies in the dorsal horn and parasympathetic intermediolateral nucleus of the rat spinal cord. Neurosci. Lett. 27: 335-339.

Dalsgaard, C.-J., S. R. Vincent, T. Hökfelt, J. M. Lundberg, A. Dahlstrom, M. Schultzberg, G. J. Dockray, and A. C. Cuello (1982) Coexistence of cholecystokinin- and substance P-like peptides in neurons of the dorsal root ganglia of the rat. Neurosci. Lett. 33: 159164.

Erichsen, J. T., A. Reiner, and H. J. Karten (1982) Co-occurrence of substance P-like and leucine enkephalin-like immunoreactivities in neurons and fibers of the avian nervous system. Nature 295: 407409.

Gibbins, I. L., J. B. Furness, and M. Costa (1987) Pathway-specific patterns of co-existence of substance $P$, calcitonin gene-related peptide, cholecystokinin, and dynorphin in neurons of the dorsal root ganglia of the guinea pig. Cell Tissue Res. 248: 417-437.

Gibson, S. J., J. M. Polak, S. R. Bloom, and P. D. Wall (1981) The distribution of nine peptides in the rat spinal cord with special emphasis on the substantia gelatinosa and the area around the central canal (lamina X). J. Comp. Neurol. 201: 65-79.

Gibson, S. J., J. M. Polak, S. R. Bloom, I. M. Sabate, P. M. Mulderry, M. A. Ghatei, G. P. McGregor, J. F. B. Morrison, J. S. Kelly, R. M. Evans, and M. G. Rosenfcld (1984a) Calcitonin gene-related peptide immunoreactivity in the spinal cord of man and eight other species. J. Neurosci. 4: 3101-3111.

Gibson, S. J., J. M. Polak, P. Anand, M. A. Blank, J. F. B. Morrison, J. S. Kelly, and S. R. Bloom. (1984b) The distribution and origin of VIP in the spinal cord of six mammalian species. Peptides 5: 201207.

Graybiel, A. M., and R. P. Elde (1983) Somatostatin-like immunoreactivity characterizes neurons of the nucleus reticularis thalami in the cat and monkey. J. Neurosci. 3: 1308-1321.

Hökfelt, T., J.-O. Kellerth, G. Nilsson, and B. Pernow (1975) Substance P: Localization in the central nervous system and some primary sensory neurons. Science 190: 889-890.

Hökfelt, T., R. Elde, O. Johansson, R. Luft, G. Nilsson, and A. Arimura (1976) Immunohistochemical cvidence for scparatc populations of somatostatin-containing and substance $P$-containing primary afferent neurons in the rat. Neuroscience 1: 131-136.

Honda, C. N., M. Rethelyi, and P. Petrusz (1983) Preferential immunohistochemical localization of vasoactive intestinal polypeptide (VIP) in the sacral spinal cord of the cat: Light and electron microscopic observations. J. Neurosci. 3: 2183-2196.

Hunt, S. P., J. S. Kelly, P. C. Emson, R. J. Kimmel, R. J. Miller, and
J.-Y. Wu (1981) An immunohistochemical study of neuronal populations containing neuropeptides or gamma aminobutyrate within the superficial layers of the rat dorsal horn. Neuroscience 6: 18831898.

Jessell, T., A. Tsunoo, I. Kanazawa, and M. Otsuka (1979) Substance P: Depletion in the dorsal horn of rat spinal cord after section of peripheral processes of primary sensory neurons. Brain Res. 168:247259.

Johansson, O., T. Hökfelt, B. Pernow, S. L. Jeffcoate, N. White, H. W. M. Steinbusch, A. A. J. Verhofstad, P. C. Emson, and E. Spindel (1981) Immunohistochemical support for three putative transmitters in one ncuron: Cocxistence of 5-hydroxytryptamine, substance $\mathrm{P}$ and thyrotropin releasing hormone-like immunoreactivity in medullary neurons projecting to the spinal cord. Neuroscience $6: 1857-1881$.

Kai-Kai, M. A., and P. Keen (1985) Localization of 5-hydroxytryptamine to neurons and endoneurial mast cells in rat sensory ganglia. J. Neurocytol. 14: 63-78.

Kumazawa, T., and E. R. Perl (1976) Differential excitation of dorsal horn substantia gelatinosa and marginal neurons by primary afferent units with fine (A and C) fibers. In Sensory Functions of the Skin in Primates, R. Zotterman, ed., pp. 67-88, Pergamon, Oxford, UK.

Kumazawa, T., and E. R. Perl (1978) Excitation of marginal and substantia gelatinosa neurons in the primate spinal cord: Indications of their place in dorsal horn functional organization. J. Comp. Neurol. 177: 417-434.

Kuo, D. C., M. Kawatani, and W. C. deGroat (1985) Vasoactive intestinal polypeptide identified in the thoracic dorsal root ganglia of the cat. Brain Res. 330: 178-182.

LaMotte, C. C. (1986) Organization of dorsal horn neurotransmitter systems. In Spinal Afferent Processing, T. L. Yaksh, ed., pp. 97-116, Plenum, New York.

LaMotte, C. C., and N. C. deLanerolle (1983) Ultrastructure of chemically defined neuron systems in the dorsal horn of the monkey. III. Serotonin immunoreactivity. Brain Res. 274: 65-77.

Larsson, L.-I. (1981) A novel immunocytochemical model system for specificity and sensitivity screening of antiserum against multiple antigens. J. Histochem. Cytochem. 29: 408-410.

Leah, J. D., A. A. Cameron, W. L. Kelly, and P. J. Snow (1985) Coexistence of peptide immunoreactivity in sensory neurons of the cat. Neuroscience 16: 683-690.

Lee, Y., Y. Kawai, S. Shiosaka, K. Takami, H. Kijama, C. J. Hillyard, S. Girgis, I. MacIntyre, P. C. Emson, and M. Tohyama (1985a) Coexistence of calcitonin gene-related peptide and substance P-like peptides in single cells of the trigeminal ganglion of the rat: Immunohistochemical analysis. Brain Res. 330: 194-196.

Lee, Y., K. Takami, Y. Kawai, S. Girgis, C. J. Hillyard, I. MacIntyre, P. C. Emson, and M. Tohyama (1985b) Distribution of calcitonin gene-related peptide in the rat peripheral nervous system with reference to its coexistence with substance P. Neuroscience 15: 12271237.

Light, A. R., and E. R. Perl (1979) Spinal terminations of functionally identified primary afferent neurons with slowly conducting myelinated fibres. J. Comp. Neurol. 186: 133-150.

Maley, B., and R. Elde (1982) Immunohistochemical localization of putative neurotransmitters within the feline nucleus tractus solitarii. Neuroscience 7: 2469-2490.

Miller, K. E., and V. S. Seybold (1987) Comparison of met-enkephalin-, dynorphin A-, and neurotensin-immunoreactive neurons in the cat and rat spinal cords: I. Lumbar cord. J. Comp. Neurol. 255: 293304.

Price, J., and A. W. Mudge (1983) A subpopulation of rat dorsal root ganglion neurones is catecholaminergic. Nature 301: 241-243.

Ribeiro-da-Silva, A., and Antonio Coimbra (1982) Two types of synaptic glomeruli and their distribution in laminae I-III of the rat spinal cord. J. Comp. Neurol. 209: 176-186.

Ribeiro-da-Silva, A., J. M. Castro-Lopes, and Antonio Coimbra (1986) Distribution of glomeruli with fluoride-resistant acid phosphatase (FRAP)-containing terminals in the substantia gelatinosa of the rat. Brain Res. 377: 323-329.

Rosenfeld, M. G., J.-J. Mermod, S. G. Amara, L. W. Swanson, P. E. Sawchenko, J. Rivier, W. W. Vale, and R. M. Evans (1983) Production of a novel neuropeptide encoded by the calcitonin gene with tissue-specific RNA processing. Nature 304: 129-135.

Salt, T. E., and R. G. Hill (1983) Neurotransmitter candidates of somatosensory primary afferent fibres. Neuroscience 10: 1083-1103. 
Sasek, C. A., V. S. Seybold, and R. P. Elde (1984) The immunohistochemical localization of nine peptides in the sacral parasympathetic nucleus and the dorsal gray commissure in the rat spinal cord. Neuroscience 12: 855-873.

Schmalbruch, H. (1986) Fiber composition of the rat sciatic nerve. Anat. Rec. 215: 71-81.

Schroder, H. D. (1984) Somatostatin in the caudal spinal cord: An immunohistochemical study of the spinal centers involved in the innervation of pelvic organs. J. Comp. Neurol. 223: 400-414.

Seybold, V. S., and R. P. Elde (1980) Immunohistochemical studies of peptidergic neurons in the dorsal horn of the spinal cord. J. Histochem. Cytochem. 28: 367-370.

Seybold, V. S., and R. P. Elde (1982) Neurotensin immunoreactivity in the superficial laminae of the dorsal horn of the rat: I. Light microscopic studies of the cell bodies and proximal dendrites. J. Comp. Neurol. 204: 89-100.

Seybold, V. S., and B. Maley (1984) Ultrastructural study of neurotensin immunoreactivity in the superficial laminae of the dorsal horn of the rat. Peptides 5: 1179-1189.

Skofitsch, G., and D. M. Jacobowitz (1985a) Galanin-like immunoreactivity in capsaicin sensitive sensory neurons and ganglia. Brain Res. Bull. 15: 191-195.

Skofitsch, G., and D. M. Jacobowitz (1985b) Calcitonin gene-related peptide coexists with substance $P$ in capsaicin sensitive neurons and sensory ganglia of the rat. Peptides 6: 747-754.

Steffanini, M., C. DeMartino, and L. Zamboni (1967) Fixation of ejaculated spermatozoa for electron microscopy. Nature 216: 173174.

Sternberger, L. A., P. H. Hardy, Jr., J. J. Cuculis, and H. G. Meyer (1970) The unlabelled antibody-enzyme method of immunohistochemistry. Preparation and properties of the soluble antigen-antibody complex (horseradish peroxidase-anti-horseradish peroxidase) and its use in the identification of spirochetes. J. Histochem. Cytochem. 18: 315-333.
Stine, S. M., H. Y. Yans, and E. Costa (1982) Evidence for ascending and descending intraspinal as well as primary sensory somatostatin projections in the rat spinal cord. J. Neurochem. 38: 1144-1150.

Sugiura, Y., C. L. Lee, and E. R. Perl (1986) Central projections of identified, unmyelinated $(\mathrm{C})$ afferent fibers innervating mammalian skin. Science 234: 358-361.

Sweetnam, P. M., J. H. Neale, J. L. Barker, and A. Goldstein (1982) Localization of immunoreactive dynorphin in neurons cultured from spinal cord and dorsal root ganglia. Proc. Natl. Acad. Sci. USA 79: 6742-6746.

Tatemoto, N., S. Rokaeus, H. Jornvall, T. J. McDonald, and V. Mutt (1983) Galanin-A novel biologically active peptide from porcine intestine. FEBS Lett. 164: 124-128.

Tuchscherer, M. M., and V. S. Seybold (1985) Immunohistochemical studies of substance $P$, cholecystokinin-octapeptide, and somatostatin in dorsal root ganglia of the rat. Neuroscience 14: 593-605.

Tuchscherer, M. M., C. Knox, and V. S. Seybold (1987) Substance P and cholecystokinin-like immunoreactive varicosities in somatosensory and autonomic regions of the rat spinal cord: A quantitative study of coexistence. J. Neurosci. 7: 3984-3995.

Wessendorf, M. W., and R. P. Elde (1985) Characterization of an immunofluorescence technique for the demonstration of coexisting neurotransmitters within nerve fibers and terminals. J. Histochem. Cytochem. 33: 984-994.

Wessendorf, M. W., and R. Elde (1987) The coexistence of serotoninand substance P-like immunoreactivity in the spinal cord of the rat as shown by immunofluorescence double labeling. J. Neurosci. 7: 2352-2363.

Wiesenfeld-Hallin, Z., T. Hökfelt, J. M. Lundberg, W. G. Forssmann, M. Reinecke, F. A. Tschopp, and J. A. Fischer (1984) Immunoreactive calcitonin gene-related peptide and substance $P$ coexist in sensory neurons to the spinal cord and interact in spinal behavioural responses of the rat. Neurosci. Lett. 52: 199-204. 